\title{
New Lipid Materials Based on Chia Emulsion Gels: Application in Meat Products
}

\author{
Pintado T*, Ruiz Capillas C and Herrero AM \\ Department of Products. Institute of Food Science, Technology and Nutrition, Spain
}

*Corresponding author: Tatiana Pintado, Department of Products. Institute of Food Science, Technology and Nutrition, Spain

\begin{tabular}{|c|c|}
\hline ARTICLE INFO & ABSTRACT \\
\hline Received: 豐 May 07, 2019 & Chia features interesting nutritional and technological properties and therefore has \\
\hline Published: 慧 May 14, 2019 & $\begin{array}{l}\text { been incorporated into different types of meat products. Particularly, it has been used to } \\
\text { develop new lipid materials based on chia emulsion gels which have enormous potential as }\end{array}$ \\
\hline $\begin{array}{l}\text { Citation: Pintado T, Ruiz Capillas C , Her- } \\
\text { rero AM. New Lipid Materials Based on } \\
\text { Chia Emulsion Gels: Application in Meat } \\
\text { Products. Biomed J Sci \& Tech Res 18(1)- }\end{array}$ & $\begin{array}{l}\text { tributes to achieving meat products with optimal technological and organoleptic properties } \\
\text { and improved lipid content. These products also contain other bioactive compounds such as } \\
\text { minerals, dietary fiber, etc. which in some cases allow nutritional and health claims within } \\
\text { the framework of European legislation. }\end{array}$ \\
\hline
\end{tabular}
2019. BJSTR. MS.ID.003088.

Keywords: Emulsion Gels; Chia; Lipid Content; Bioactive Compound; Meat

Abbreviations: SFA: Saturated Fatty Acid; O/W: Oil-in-Water; MUFA: Monounsaturated Fatty Acid; PUFA: Polyunsaturated Fatty Acid

Products; Nutritional; Health Claims

\section{Introduction}

Sensitivity to public health issues worldwide has been growing over the past year and, as a consequence, the demand for functional food with multiple health benefits is on the rise. Salvia Hispanica $L$, commonly known as chia, is an example of a traditional food, native to northern Guatemala and southern Mexico, whose consumption is increasing due to its numerous health benefits. In 2009, chia seed was considered a novel food under Regulation (EC) No 258/97 of the European Parliament [1]. Its nutritional value derives mainly from the high concentrations of essential fatty acids (mainly $\alpha$-linolenic fatty acid), dietary fiber, proteins of high biological value, antioxidants, vitamins, carotenoids and minerals. Another key feature of chia seed is that it is gluten free [2]. Chia also promotes nutrition by raising the satiety index thus helping to prevent cardiovascular disease, diabetes and other disorders [2,3]. Moreover, the incorporation of chia to food products not only improves nutritional and health properties but can also confer interesting technological properties that include, among others, high water-holding capacity and emulsification and gelling activity $[2,4,5]$.

\section{Chia in Meat Products}

\section{Chia Added Directly to Meat Products}

Chia can be used as whole chia seeds and chia flour, soaked in water or dry depending on the application. Whole chia seed can be consumed directly byadding them to salads, yogurt or beverages and, in both whole seed and flour form, can also be used as an ingredient in the elaboration of healthy foods [6]. Meat products have been fortified with chia to improve their nutritional profile while taking advantage of its technological properties during processing. By way of example, a chia by-product (defatted chia flour) has been added in differing proportions directly to hamburger as a way to increase its $\alpha$-linolenic content [7]. The direct incorporation of chia seed $(1 \%)$ in low fat restructured ham-like products not only enhanced nutritional composition but also improved physico-chemical and sensorial properties [8]. Chicken nuggets containing 10\% chia flour were considered acceptable from a sensorial perspective and technological characteristics such as hardness, cooking yield and 
water activity were similar to those of control samples [9]. With respect to its technological properties, some authors [10] studied the effect of chia seed extract at concentrations of $0 \%, 1 \%, 1.5 \%$ and $2 \%$ as an antioxidant in fresh pork sausage with favorable results.

\section{Chia Emulsion Gels as Animal Fat Replacers in Meat Products}

Meat products in general contains a high amount of animal fat that not only increases their energy value but also raises levels of saturated fatty acid (SFA), cholesterol, etc. which have been linked to chronic disorders (obesity, cardiovascular disease and some forms of cancer) [11]. Novel proposals for oil stabilization and structuring to create a plastic fat as an emulsion gel, which retains solid-like properties while featuring a healthier fatty acid profile, offers interesting possibilities for use as animal fat replacers in the reformulation of lipid healthier meat products [12]. An emulsion gel is defined as an emulsion with a gel-like network structure and solid-like mechanical properties [13]. The initial stage in emulsion gel formulation usually consists of producing a protein-stabilized emulsion that involves the incorporation of an emulsification stabilizer (protein, polysaccharide, surfactant, etc.) and a lipid phase composed of a healthy fatty acid oil or mix. This emulsion is then converted into an emulsion gel using different procedures such as the addition of cold gelling agents which establish a continuous network responsible for the functional properties of emulsion gels [13]. Chia offers interesting possibilities in the development of emulsion gels due to its high protein content (20-22\%) and mucilage, described with emulsifying, gelling and stabilizing effect $[4,14]$.

Pintado et al. [5] developed and characterized various healthy oil-in-water $(\mathrm{O} / \mathrm{W})$ emulsion gels formulated with olive oil and chia (flour or seed) and cold gelling agents (transglutaminase, alginate or gelatin) with suitable technological properties (texture, water and fat binding properties, etc.) for use as animal fat replacers (Figure 1). In addition to its technological properties, the inclusion of chia $(5 \%)$ in these new lipid materials provided a variety of bioactive compounds ( $\alpha$-linolenic fatty acids, proteins of high biological value, antioxidants, dietary fiber, minerals, etc.). On the basis of the foregoing, these emulsion gels show great potential as animal fat replacers in the formulation of healthier meat products. By way of example, reduced fat frankfurters have been elaborated with $0 / \mathrm{W}$ emulsion gels that contained $5 \%$ chia flour as animal fat replacer [15]. With this strategy, the fat level was reduced to $40 \%$ (Figure 2), thus achieving a reduction of approximately $30 \%$ in energy input. Moreover, chia emulsion gels significantly improved the fat content of frankfurters in line with nutritional recommendations, in terms of low levels of SFA and high levels of monounsaturated fatty acid (MUFA) and n-3 polyunsaturated fatty acid (PUFA), mainly $\alpha$-linolenic fatty acid (Figure 2). Also, reformulated frankfurters contained considerable amounts of some minerals such as $\mathrm{Mg}$, Mn, and Ca. Emulsion gels with higher chia content (25.84\%) were also used as animal fat replacers to assure nutritional and health benefits in frankfurters [16].

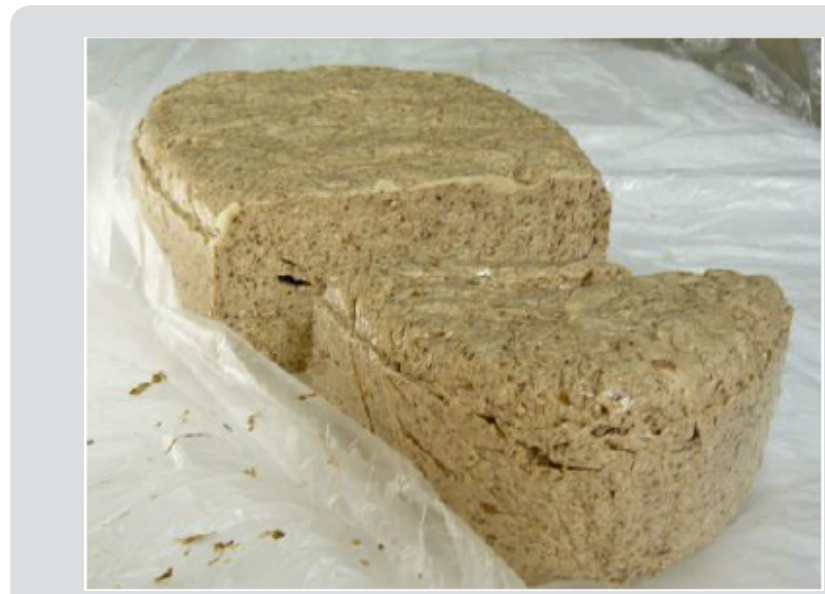

Figure 1: Chia emulsion gel.

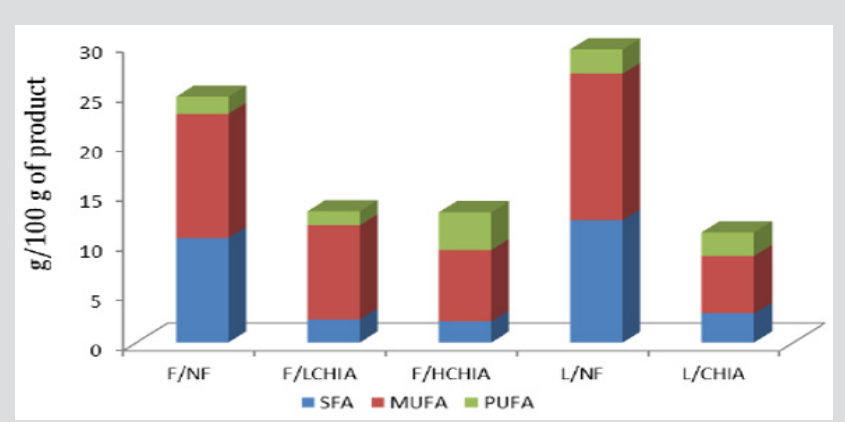

Figure 2: Fatty acid composition (g/100 $\mathrm{g}$ of product) of frankfurter (F) and fresh sausages (longanizas) (L). Frankfurters were formulated with pork backfat (F/NF), or chia emulsion gel, as animal fat replacer, containing low (F/LCHIA) or high (F/HCHIA) chia content. Fresh sausages (longanizas) were formulated with pork backfat (L/NF) or chia emulsion gel (L/CHIA) as animal fat replacer.

Given these nutritionalimprovements, products could belabeled with a variety of nutritional and health claims under Regulation (EC) No 1924/2006 and Regulation (EU) 432/2012 [17,18] \& (Table 1). Besides the nutritional aspects, these reformulation strategies entail changes in the technological characteristics of the products, improving some such as water and fat binding properties. Furthermore, although differences were detected in the sensory attributes of reformulated frankfurters, panelists judged them to be acceptable from a sensorial perspective $[15,16]$. Emulsion gels have proven to be especially suitable in improving fat content in some fresh meat products such as patties, fresh sausages, etc., where the appearance and structure of fat replacers are more important than in comminuted products as frankfurters. In this context, chia emulsion gels were incorporated to partially replace animal fat in longanizas, a popular fresh sausage in Spain [19]. No detrimental changes in their sensory or technological properties were observed in the reformulated products (Figure 3). The presence of chia emulsion 
gel in reformulated fresh sausages entails reduced fat and energy content allowing these products to make claims such as "reduced fat content" and "energy reduced" (Table 1) and significantly improve fat content in line with nutritional recommendations, given their low levels of SFAs and high levels of MUFA and PUFA ( $\alpha$-linolenic fatty acid mainly) (Figure 2). Additionally, $5.4 \mathrm{~g}$ chia/100 g fresh sausages contributed to a significant increase in minerals such as $\mathrm{Ca}$ and $\mathrm{Mg}$ and amino acids such as aspartic acid, serine, glutamic acid and arginine in the final reformulated products.

Table 1: Nutrition and health claims authorized in frankfurters and fresh sausages (longanizas) according to Regulation (EC) No 1924/2006 and Commission Regulation (EU) No 432/2012.

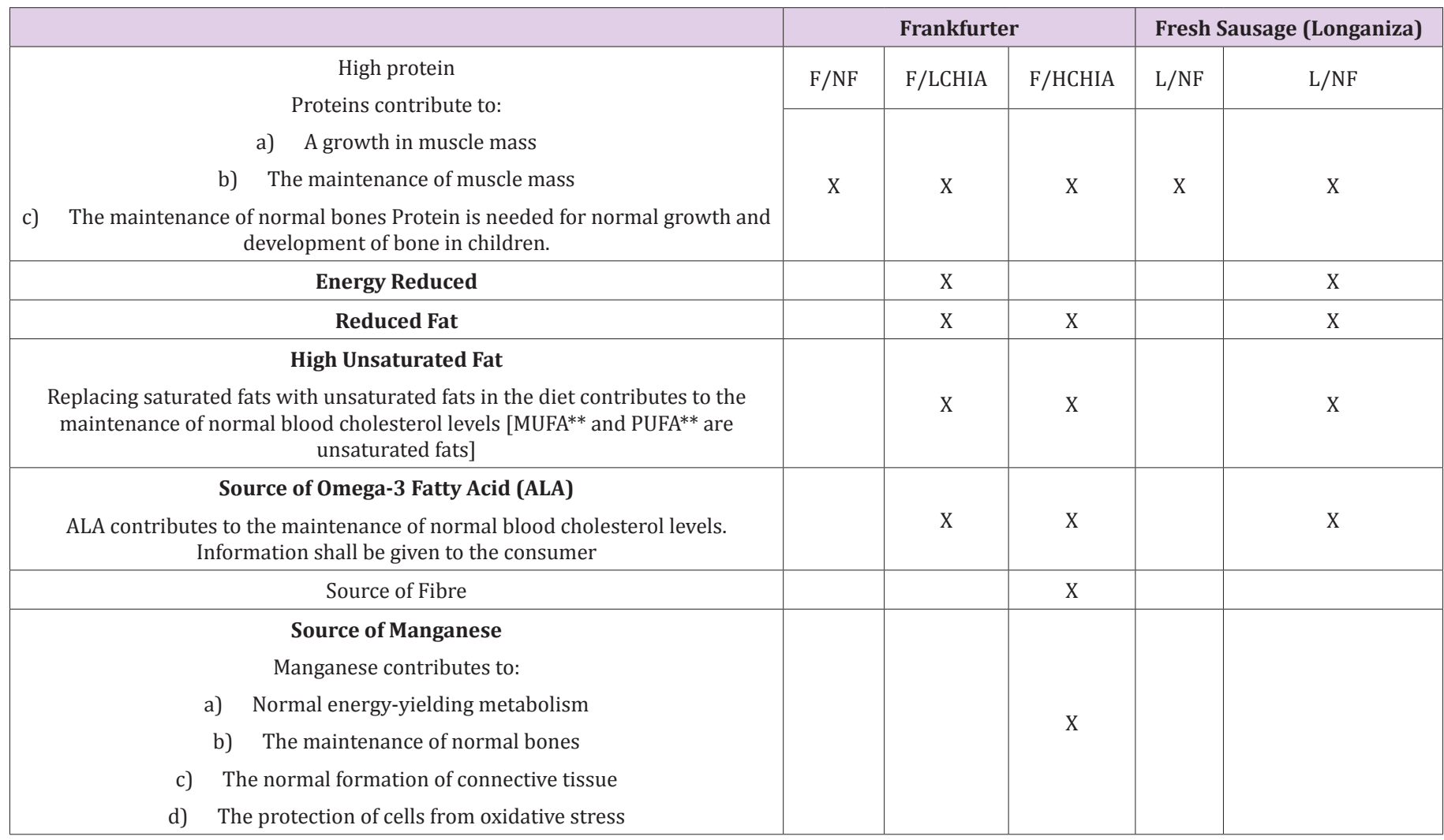

Note: *Frankfurters $(\mathrm{L})$ were formulated with pork backfat $(\mathrm{F} / \mathrm{NF})$, or chia emulsion gels as animal fat replacer containing low (F/LCHIA) or high (F/HCHIA) chia content. Fresh sausages (Longanizas) (L) were formulated with pork backfat (L/NF) or chia emulsion gel as animal fat replacer (L/CHIA).

**MUFA: Monounsaturated fatty acid. PUFA: Polyunsaturated fatty acid.

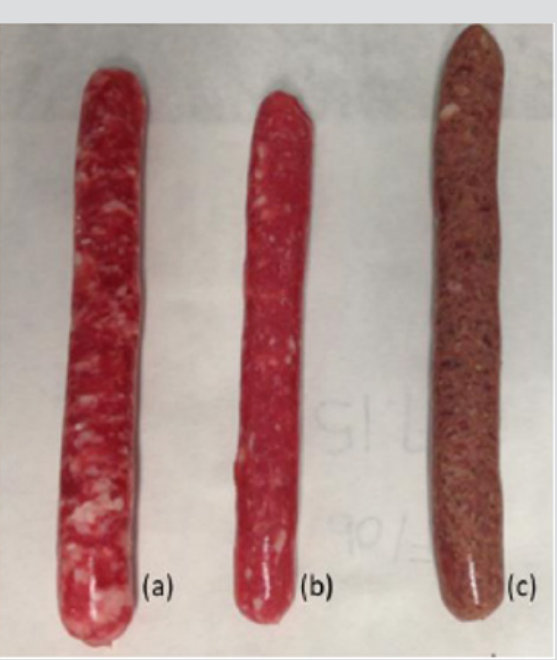

Figure 3: Fresh sausages (longanizas) elaborated with normal (a) or reduced pork backfat content (b) and with chia emulsion gels as animal fat replacer (c).

\section{Conclusion}

The incorporation of chia in meat products improves their nutritional profile. Moreover, due to interesting technological properties, chia could be used in the development of new lipid materials such as emulsion gels. These lipid materials have a great potential as animal fat replacers in the development of different meat products. This reformulation strategy helps produce meat products with optimal lipid content (less fat and higher MUFA and PUFA levels) and other bioactive compounds such as minerals ( $\mathrm{Ca}, \mathrm{Mg}, \mathrm{Mn}$, etc.), dietary fiber, etc. In some cases, this allows the use of nutritional and health claims under European legislation. The sensory, microbiological and technological properties of the reformulated products are similar to those of their traditional counterparts.

\section{Acknowledgement}

This research was supported under Projects AGL2010-19515/ ALI, AGL2011-29644-C02-01, MEDGAN-CM S2013/ABI2913; Intramural project CSIC 2014470E073. 


\section{References}

1. European Commission (2009) Commission Decision of 13 October 2009 authorizing the placing on the market of Chia seed (Salvia hispanica) as novel food ingredient under Regulation (EC) No 258/97 of the European Parliament and of the Council. Official Journal of the European Union L 294/14: 14-15.

2. Muñoz LA, Cobos A, Diaz O, Aguilera JM (2013) Chia seed (Salvia hispanica): An ancient grain and a new functional food. Food Rev Int 29(4): 394-408.

3. Ali NM, Yeap SK, Ho WY, Beh BK, Tan SW, et al. (2012) The promising future of chia, Salvia hispanica L. J Biomed Biotechnol 171956.

4. Coorey R, Tjoe A, Jayasena V (2014) Gelling properties of chia seed and flour. J Food Sci 79(5): 859-866.

5. Pintado T, Ruiz Capillas C, Jiménez-Colmenero F, Carmona P, Herrero AM (2015) Oil-in-water emulsion gels stabilized with chia (Salvia hispanica, L.) and cold gelling agents: Technological and infrared spectroscopic characterization. Food Chem 185: 470-478.

6. Zettel V, Hitzmann B (2018). Applications of chia (Salvia hispanica L.) in food products. Trends Food Sci Tech 80: 43-50.

7. Souza AHP, Gohara AK, Rotta EM, Chaves MA, Silva CM, et al. (2015) Effect of the addition of chia's by-product on the composition of fatty acids in hamburgers through chemometric methods. J Sci Food Agr 95(5): 928-935.

8. DingY, Lin HW, Lin, YL, Yang DJ, Yu YS, etal. (2018) Nutritional composition in the chia seed and its processing properties on restructured ham-like products. J Food Drug Anal 26(1): 124-134.

9. Barros JC, Munekata PES, Pires MA, Rodrigues I, Andaloussi OS, et al. (2018) Omega-3-and fibre-enriched chicken nuggets by replacement of chicken skin with chia (Salvia hispanica L.) flour. LWT-Food Sci Technol 90: 283-289.

10. Scapin G, Schimdt MM, Prestes RC, Ferreira S, Silva AFC, et al. (2015) Effect of extract of chia seed (Salvia hispanica) as an antioxidant in fresh pork sausage. Int Food Res J 22(3): 1195-1202.

\section{ISSN: 2574-1241}

DOI: 10.26717/BJSTR.2019.18.003088

Tatiana Pintado. Biomed J Sci \& Tech Res

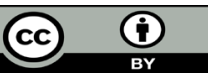

This work is licensed under Creative Commons Attribution 4.0 License

Submission Link: https://biomedres.us/submit-manuscript.php
11. Wood JD, Richardson RI, Nute GR, Fisher AV, Campo MM, et al. (2004) Effects of fatty acids on meat quality: A review. Meat Sci 66(1): 21-32.

12. Jiménez Colmenero F, Salcedo-Sandoval L, Bou R, Cofrades S, Herrero AM, et al. (2015) Novel applications of oil-structuring methods as a strategy to improve the fat content of meat products. Trends Food Sci Tech 44(2): 177-188.

13. Dickinson E (2012) Emulsion gels: The structuring of soft solids with protein stabilized oil droplets. Food Hydrocolloid 28(1): 224-241.

14. Capitani MI, Spotorno V, Nolasco SM, Tomás MC (2012) Physicochemical and functional characterization of by-products from chia (Salvia hispanica L.) seeds of Argentina. LWT-Food Sci Technol 45(1): 94-102.

15. Pintado T, Herrero AM, Ruiz Capillas C, Triki M, Carmona P, et al. (2016) Effects of emulsion gels containing bioactive compounds on sensorial, technological, and structural properties of frankfurters. Food Sci Technol Int 22(2): 132-145.

16. Pintado T, Herrero AM, Jiménez Colmenero F, Ruiz Capillas C (2016) Strategies for incorporation of chia (Salvia hispanica L.) in frankfurters as a health-promoting ingredient. Meat Sci 114: 75-84.

17. European Commission (EC) (2006) Regulation (EC) no 1924/2006 of the European Parliament and of the council of 20 December 2006 on nutrition and health claims made on foods. Official Journal of the European Union, p. 3-18.

18. European Union (EU) (2012) Commission Regulation (EU) no $432 / 2012$ of the European Parliament and of the Council of 16 May 2012 establishing a list of permitted health claims made on foods other than those referring to the reduction of disease risk and to children's development and health. Official Journal of the European Union, p. 1-40.

19. Pintado T, Herrero AM, Jiménez Colmenero F, Pasqualin Cavalheiro C, Ruiz Capillas C (2018) Chia and oat emulsion gels as new animal fat replacers and healthy bioactive sources in fresh sausage formulation. Meat Sci 135: 6-13.

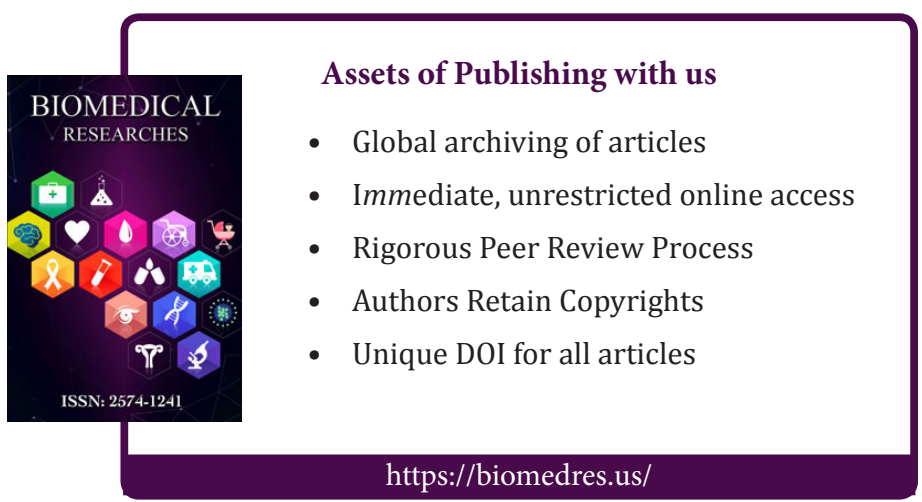

